RELACult - Revista Latino-Americana de Estudos em Cultura e Sociedade

Revista Latinoamericana de Estudios en Cultura y Sociedad | Latin American Journal of Studies in Culture and Society

V. 02, Ed. Especial, dezembro, 2016, p. 547-555 | periodicos.claec.org e-ISSN 2016/Atual: 2525-7870 | e-ISSN 2015/2016: 2447-018X

\title{
Território Indígena: a construção diária da sobrevivência
}

\author{
Territorio indígena: la construcción diaria de la supervivencia \\ Indigenous Territory: the daily construction of survival
}

\author{
Elenice Costa da Silveira ${ }^{1}$ \\ Lóry da Silveira Ribeiro ${ }^{2}$ \\ Gilson Antonio Morais ${ }^{3}$ \\ Ma. Elisabete da Silveira Ribeiro ${ }^{4}$
}

\begin{abstract}
Resumo
O presente trabalho tem como objetivo principal provocar a discussão à cerca do território indígena no contexto atual do país. É notória a violência contra os povos indígenas no Brasil, no entanto percebemos um silenciamento terrível em relação a este assunto, comprometidos com esta causa temos buscado compreender melhor a questão do território indígena. Para tanto, temos nos proposto não só a fazer leituras sobre o tema como procurado encontrar diferentes sujeitos que integram estes povos, na tentativa de entender como estes percebem a situação que se apresenta. Fundamentando este trabalho dialogamos principalmente com Milton Santos, Paulo Freire e Genilson Nolasco.
\end{abstract}

Palavras-chaves: indígenas; território; violência.

\section{Resumen}

Este trabajo tiene como objetivo provocar la discusión sobre el territorio indígena en el contexto actual del país. Es notorio la violencia contra los pueblos indígenas de Brasil, sin embargo, nos dimos cuenta de un terrible silenciamiento respecto a esta materia, comprometida con esta causa hemos tratado de comprender mejor la cuestión del territorio indígena. Por lo tanto, hemos propuesto no sólo para tomar lecturas sobre el tema y ha tratado de encontrar diferentes temas que forman parte de estas personas, tratando de comprender cómo perciben la situación en cuestión. Basando este trabajo en diálogo principalmente con Milton Santos, Paulo Freire y Genilson Nolasco.

Palabras clave: Indígena; territorio; violencia.

\section{Abstract}

This work aims to provoke discussion about the indigenous territory in the current context of the country. It is notorious for violence against indigenous peoples in Brazil, however we noticed a terrible silencing regarding this matter, committed to this cause we have sought to better understand the issue of indigenous territory.

\footnotetext{
1 Universidade Federal do Rio Grande do Sul - UFRGS; Porto Alegre, Rio Grande do Sul, Brasil; elenicecsilveira@hotmail.com.
}

${ }^{2}$ Graduanda em Educação Física; Universidade Federal do Rio Grande - FURG; Rio Grande, Rio Grande do Sul, Brasil; 10ry94@gmail.com.

3 Universidade Federal do Rio Grande - FURG; Rio Grande, Rio Grande do Sul, Brasil; gilsonantoniomorais@gmail.com.

4 Mestrado em Educação; Universidade Federal do Tocantins - UFT; Arraias, Tocantins, Brasil; btsilveira@uft.edu.br. 
Therefore, we have proposed not only to take readings on the subject and sought to find different subjects that are part of these people, trying to understand how they perceive the situation at hand. Basing this work we dialogue mainly with Milton Santos, Paulo Freire and Genilson Nolasco.

Keywords: Indigenous; Territory; violence.

\section{Introdução}

Este trabalho tem a intenção de chamar a atenção e provocar discussão sobre o território indígena na atual conjuntura brasileira. Para tanto, chamamos ao diálogo Paulo Freire, Milton Santos e Genilson Nolasco.

No Fórum de Leituras de Paulo Freire, ocorrido em Jaguarão, no Rio Grande do Sul, recentemente passado denunciávamos a recorrente violência contra os povos indígenas. Esta escrita tem o mesmo cunho, pois logo após o Fórum, em junho fomos ao I Seminário de Educação do Campo da Universidade Federal de Uberlândia e, na ocasião tivemos o privilégio de participarmos de uma oficina com o Cacique Maximino Rodrigues o qual apresentou-nos a face da violência dos latifundiários no Mato Grosso do Sul contra os indígenas da etnia Guarani-Kaiowás.

O território indígena tem sido cada vez mais invadido por donos de grandes fazendas, mineradoras e outras empresas multinacionais e estes vão sendo cada vez mais expulsos de suas terras. Cresce a violência, principalmente expressa em assassinatos e suicídios desses povos de comunidades tradicionais do Brasil.

No entanto, percebe-se um silenciamento e uma conivência em relação a esses atos, tanto pela sociedade em geral quanto pelo governo. Existe uma permissividade de violência contra os povos indígenas.

Isto nos faz, sempre que possível tentar fomentar a discussão sobre essa situação tão cruel, na tentativa de dar mais visibilidade ao assunto. Porém, não é uma discussão tranquila, já que, de um lado há uma negação de que isto realmente aconteça e de outro, preconceitos cada vez mais vultosos a cerca desses povos.

\section{Território indígena e resistência}

Somos milhões de companheiros e companheiras buscando a libertação da terra, de homens e mulheres em um país onde a terra vale ouro e os seres humanos, alguns gramas de chumbo moldados em balas que fazem sangrar o destino do nosso povo sofredor!

Pedro Tierra 
Entendendo o território carregado de sentidos humanizados, arraigados à cultura, com toda a sua complexidade, concordamos com o significado de território, expresso por Milton Santos (2002, p. 9) quando diz que

\begin{abstract}
a geograficidade se impõe como condição histórica, na medida em que nada considerado essencial hoje se faz no mundo que não seja a partir do conhecimento do que é Território. O Território é o lugar em que desembocam todas as ações, todas as paixões, todos os poderes, todas as forças, todas as fraquezas, isto é onde a história do homem plenamente se realiza a partir das manifestações da sua existência.
\end{abstract}

Para nós território e territorialidade humana estão imbricados, precisamos de estudos que como diz Saquet (2009, p.73)

\begin{abstract}
Reconheçam, simultaneamente, características fundamentais do processo de produção do território assim como as relações de poder, as identidades simbólicoculturais (traços comuns), as contradições, as desigualdades (ritmos lentos e rápidos), as diferenças, as mudanças (descontinuidades), as permanências (continuidades), as redes de circulação, de comunicação e a natureza interior e exterior ao homem como ser genérico (biológica e socialmente).
\end{abstract}

Por isso é que vimos a necessidade de discutir território indígena no Brasil, pois este tem sido cada vez mais reduzido e expropriado, temos presenciado nos últimos tempos uma verdadeira invasão e genocídio dos povos indígenas. Não queremos nem podemos assistir a esta situação calados como se muito pouco ou nada tivesse a ver conosco. Pois, em diferentes estados brasileiros temos presenciado muita violência e sufocamento da cultura indígena.

Estivemos no Seminário de Educação do Campo em Uberlândia onde, em oficina sobre a cultura Guarani Kaiowá o Cacique Maximino Rodrigues, desta etnia, emocionado apresenta, além de alguns segredos do seu povo, os episódios de violência pelos quais estão passando. Não apenas conta, também apresenta vídeos que mostram a truculência e a crueldade dos grandes fazendeiros do Mato Grosso do Sul, que continuam invadindo as reservas indígenas e matando friamente sujeitos daquele povo.

Maximino mostra as barracas em que os indígenas estão vivendo, em péssimas condições, fala com olhos marejados que aquilo não é casa digna para o seu povo, que vai sendo cada vez mais sendo expulso de suas terras, tendo que construir a luta diariamente.

Em seguida nos choca, ao mostrar um vídeo em que um jagunço de fazendeiro atira nos indígenas, atingindo em cheio um homem, o moço cai e não contente o empregado da fazenda vem de trator e bate com uma esteira neste que morre se debatendo, na frente dos parentes sem que estes possam fazer nada. Outro menino indígena é atingido por balas na 
coluna e na cabeça, os indígenas desesperados pedem um carro para tentar socorrê-lo, o carro não chega...

Alguns dias depois é a vez do próprio cacique Maximino ser "avisado" de que será o próximo a morrer. A esposa e a filha que também participam da oficina, em que ele nos conta tal sentença, choram. Sabem que esse futuro poderá chegar logo.

Nós que estamos na sala ficamos estarrecidos e questionamos: Por que não denunciam a justiça?. Melhor seria não ter feito tais perguntas. Maximino, não esconde a tristeza, conta que sempre denunciam, mas que nenhum crime cometido contra indígena no Brasil teve desfecho de condenar os mandantes ou os executores. Saímos da sala calados, com uma tristeza que não cabia em nós. Era como se morremos um pouco a cada história que tínhamos conhecido na atividade daquela tarde em Uberlândia, junto com esse povo tão invizibilizado e que continua sendo o "outro" que não precisa ser respeitado, o "exótico", o que não tem sentimentos e muito menos direitos.

Lembramos ainda do menino Vitor que aos dois anos de idade, enquanto mamava, em dezembro do ano passado, foi assassinado em Chapecó, Santa Catarina. Teve sua vida interrompida de forma estupida, pelo simples fato de ser indígena e de viver numa sociedade que não os reconhece como gente. Esta morte passou despercebida. Por quê? Segundo a jornalista Eliane Brum, do jornal espanhol El País (2016), porque era indígena. Eliane emocionada denuncia, as evidencias de um crime cometido e reafirmado pela sociedade:

Se fosse meu filho, ou de qualquer mulher branca de classe média, assassinado nessas circunstâncias, haveria manchetes, haveria especialistas analisando a violência, haveria choro e haveria solidariedade. E talvez houvesse até velas e flores no chão da estação rodoviária, como nas vítimas de terrorismo em Paris. Mas Vitor era um índio. Um bebê, mas indígena. Pequeno, mas indígena. Vítima, mas indígena. Assassinado, mas indígena. Perfurado, mas indígena. Esse "mas" é o assassino oculto. Esse "mas" é serial killer.

Do mesmo modo que a sociedade em geral, o governo que deveria ser agente de promoção de direitos de cidadania aos indígenas, age contraditoriamente, principalmente no contexto político atual que traz como centralidade o agronegócio, tão propagado pela imprensa lucrativa, que diz claramente "agronegócio é tudo", a violência contra o povo indígena é tão naturalizada que não parece violenta. Continuamos a ver a grande mídia a quando não invizibilizá-los, apresentá-los como desordeiros, baderneiros, preguiçosos, outros termos pejorativos, traduzindo a ideia de que são, principalmente, dispensáveis.

A pressão é constante sobre as terras indígenas. Segundo Nolasco (2016, p. 105) 
As atenções do agronegócio (...) e o incentivo do governo federal tendem a ampliar a pressão sobre as terras indígenas e seus recursos naturais. Nesse contexto, ao invés de compatibilizar esse modelo de desenvolvimento à preservação dos recursos naturais e às áreas de preservação destinadas a um uso culturalmente estabelecido como Terras Indígenas, os governos federal e estadual parecem caminhar em sentido contrário.

É perceptível que a situação se agrava e a disputa pela terra para o agronegócio é a centralidade do processo de violência contra os indígenas que as diferentes etnias, de norte a sul do país estão vivendo. O mais sórdido dessa realidade é que ela está sendo naturalizada, como se nada tivesse a ver com os não indígenas.

Por exemplo, os estados do Maranhão, Tocantins, Piauí e Bahia estão entrando no famoso MATOPIBA que nada mais é do que a entrega de terras de comunidades tradicionais ao agronegócio, às transnacionais, aos monocultores de soja e eucalipto, com a pretensa desculpa de estarem resgatando as culturas das comunidades tradicionais. Todavia, cultura não precisa ser resgatada, está lá na cotidianidade das pessoas. Além disso, questionamos: desde quando as grandes empresas preocupam-se com culturas tradicionais se a centralidade destas é o lucro desmedido?

O território indígena tem sofrido com a ação perniciosa de não indígenas, situação que segundo o Cacique Maximino é difícil de entender, pois eles sentem-se pertencentes à terra, a qual tem uma relação de muito respeito e não de dominação. O território conforme Milton Santos (1198, p.08), como “o sentimento de pertencer àquilo que nos pertence”.

Estes povos tiveram seus mundos, suas histórias invadidas e continuam tendo. Sendo que parece que ainda mais nos últimos tempos, inclusive com o aval de escritas pretensamente científicas como denuncia Leia Ramos, da etnia Macuxi que revela que em seu processo de doutoramento tem que ler alguns autores que apresentam uma visão completamente preconceituosa do povo indígena. O que por si só já configura uma violência.

Paulo Freire (2000, p.31) em sua Pedagogia da Indignação, com profunda tristeza, já denunciava a crueldade cometida por jovens de classe média, em Brasília, em 1997, contra Galdino um indígena que por não ter onde dormir passava a noite em uma estação rodoviária

Cinco adolescentes mataram hoje, barbaramente, um índio pataxó, que dormia tranquilo, numa estação de ônibus, em Brasília. Disseram à polícia que estavam brincando. Que coisa estranha. Brincando de matar. Tocaram fogo no corpo do índio como quem queima uma inutilidade. Um trapo imprestável.

Reafirmamos o que já havíamos dito antes, passaram-se dezenove anos e a denúncia de Freire continua atual, pois mês a mês muitos "Galdinos" são assassinados e os povos 

e-ISSN 2016/Atual: 2525-7870 | e-ISSN 2015/2016: 2447-018X

indígenas são desrespeitados de muitas maneiras. Cresce dia a dia o número de conflitos pela terra de que são expropriados e o desrespeito às suas culturas é evidente.

Desse modo, entendemos o recente alto índice de suicídios entre os jovens indígenas da etnia Iny Karajá, ocorridos na Ilha do Babanal, no estado do Tocantins. A violência contra eles é tanta que a vida acaba perdendo o sentido. No fundo, todos somos responsáveis por essas mortes, pois não fizemos nada para impedi-las. Concordamos com SANTOS (2015) quando suplica:

\begin{abstract}
Não me deem motivos para ir embora! Por favor, construam e exponham para mim argumentos suficientemente convincentes para que eu deseje permanecer em um mundo onde os seres humanos disputam sem nem mesmo saber pelo que estão disputando; onde creio que tantas pessoas estejam diariamente realizando 'o bom combate' Acordei (...) com uma imensa vontade de escrever sobre a insensibilidade com que são tratadas as pessoas mais sensíveis; com uma 'querência' enorme de não viver em uma 'sociedade de poetas mortos'.
\end{abstract}

Os indígenas, na realização cotidiana do bom combate, continuam sem entender essa lógica destrutiva, já que a convivência deles com o ambiente e com as outras pessoas é muito mais receptiva. Maximino nos conta, por exemplo, que eles ao entrarem na floresta para procurar alimentos ou realizar alguma outra atividade pedem licença a esta, pois entendem que são apenas parte deste conjunto em que habitam outros seres.

Para Santos, Machado e Bicalho (2016, p.132)

\begin{abstract}
O suicídio entre os Iny Karajá resulta do desdobramento decorrente do descaso histórico do pode público e dos grupos dirigentes em relação à saúde pública, sobretudo, do povos indígenas. Logo, é apreendida como violência institucional, o que contribui para o crescimento desse tipo de morte entre diversas etnias no Brasil e em outros países.
\end{abstract}

Nos últimos anos tem crescido tanto a taxa de suicídios entre jovens indígenas, em diversos países, que este foi o tema do Fórum Permanente sobre Assuntos Indígenas da ONU, realizado em abril de 2015 em NovaYork, nos Estados Unidos. Para se ter uma ideia, no Brasil, entre os Guarani Kaiwá de 2000 a 2014 foram registrados 707 mortes por suicídio, ou seja, muito mais elevada do que a taxa dos não indígenas ratificando o que diz o documento do Fórum da ONU (2015) “(...) los pueblos indígenas experimentan tasas despropocionadamente altas de suicidio de de jóvenes".

Nesse documento fica clara a concepção que o fenômeno está intrinsecamente ligado à colonização. Segundo o Fórum da ONU (2015): 

e-ISSN 2016/Atual: 2525-7870 | e-ISSN 2015/2016: 2447-018X

Las injusticias históricas, como resultado de lá colonización y la confiscación de las tierras, territorios y recursos que muchos pueblos indígenas han sufrido y siguien sufriendo, en gran medida no han sido resueltas. Eso há tenido efectos negativos sobre los pueblos indígenas de muchas maneras, incluidos los que afectan su bienestar físico y mental, particularmente sobre los jóvenes que, a menudo, están frustrados con los problemas adiocionales que enfrentan debido a su propria identidad y cultura. (...) en muchos casos, la marginación ha disparado el abuso de drogas y alcohol, la violencia doméstica y gran catidad de otras condiciones traumáticas. En última instancia esas condiciones son así sufridas por los jóvenes indígenas, presentándose en múltiples formas, incluidos la autolesión y el suicídio.

Como é possível perceber o suicídio acaba sendo a saída encontrada por jovens que perdem seu espaço, seu território, vem sua cultura ameaçada sem compreender esse continuo processo de colonização violenta não indígena. Este fenômeno precisa com urgência ter visibilidade, para não continuarmos sendo coniventes com o genocídio indígena que vem ocorrendo.

Para Santos (2005, p.255) "o uso do território, e não o território em si mesmo, que faz dele objeto de análise social, sinônimo de espaço humano, espaço habitado.” A construção de territorialidade indígena é diferente da do não indígena, é a de pertencimento à terra. Talvez este seja o seu maior pecado, na lógica do capital, onde a terra não tem função social, mas de troca, de mercado, de agronegócio, onde as pessoas pouco importam.

Nolasco (p. 100. 2016) enfatiza que:

A Constituição Federal, aprovada em de outubro de 1988, é um marco para os direitos dos povos indígenas no Brasil, principalmente em reação ao território, pois até então a legislação brasileira determinava a integração das populações indígenas à sociedade nacional, com o objetivo de transformá-las em não indígenas e, assim, supostamente, perderiam o direito aos territórios tradicionais. Entretanto, desde a promulgação da nova carta constitucional passou a ser dever do Estado brasileiro assegurar e reconhecer os direitos indígenas à posse de suas terras tradicionalmente ocupadas.

No entanto, mesmo com o direito previsto na Constituição Federal o que continua se vendo é uma luta diária dos indígenas para não serem expulsos de suas terras, o que frequentemente acontece pela ação de grandes fazendeiros, de garimpeiros, de mineradoras, hidrelétricas, entre outros. Ou seja, o mecanismo legal está estabelecido, porém a garantia desse direito está longe de ser exercida.

Nolasco (2016, p. 107) lamenta que

ao revisitarmos a história do contato dos povos indígenas com os não indígenas, percebemos um processo violento de invasão das terras tradicionais indígenas, de extermínio e de redução drástica de suas populações e de seu confinamento em territórios circunscritos. Esses povos chegam ao século XXI enfrentando vários desafios para a manutenção dos recursos naturais existentes em suas terras. 
Ainda corremos o risco de ouvir, como já ouvimos em Pelotas, que os indígenas da etnia Caingangue, enfeiam a cidade quando precisam ficar, como estão no momento, a beira da BR em frente a rodoviária. Para essas pessoas talvez fosse melhor que eles simplesmente desaparecessem, escondendo de suas consciências a violência que diariamente vem ocorrendo com os indígenas no Brasil.

Esse grupo de indígenas que não está permanentemente numa área estabelecida nos preocupa ainda mais, já que a violência contra eles é ainda mais invisível, pois, segundo os próprios parentes, não aparece nos registros oficiais, estando mais fragilizados ainda. Enfim, esta é uma situação bastante difícil que temos que enfrentar todos juntos.

\section{Concluindo}

Para fins de fechar esta escrita, gostaríamos de dizer que entendemos que a violência contra os povos indígenas, mundo a fora, na América Latina e, principalmente no Brasil fazem parte da continua colonização dos territórios desses povos.

Estamos passando por um processo intenso de expulsão dos indígenas de suas terras e com isso de sufocamento de seus modos de construir cotidianamente a própria vida e de seus familiares, enfim um silenciar de suas culturas.

Denunciamos ainda a falta de um olhar cuidadoso da justiça, já que crimes contra indígenas não são devidamente julgados neste país. Assim como, a falta de ação do poder público executivo na garantia de direitos constitucionais, como saúde, educação e habitação.

Esta parcela da população não pode continuar sendo esquecida, sufocada, assassinada, precisamos de uma vez por todas ombrear junto com as comunidades indígenas para que os povos tradicionais do Brasil continuem a existir de forma saudável, dentro de suas culturas e de seu território. O território entendido como produto e produtor das relações sociais cotidianas, localizado no tempo e no espaço, com todas as suas contradições.

A nossa denúncia e permanente discussão sobre as questões indígenas estão intrinsecamente ligadas às nossas concepções de humanidade e da busca por um mundo mais justo para todos. Não podemos mais permitir que jovens indígenas brasileiros tirem suas próprias vidas por falta de perspectiva, assim como não podemos mais assistir aos seus assassinatos como se isso não tivesse nada a ver conosco, precisamos deixar de ser uma sociedade omissa e cruel. 
RELACult - Revista Latino-Americana de Estudos em Cultura e Sociedade

Revista Latinoamericana de Estudios en Cultura y Sociedad | Latin American Journal of Studies in Culture and Society V. 02, Ed. Especial, dezembro, 2016, p. 547-555 | periodicos.claec.org e-ISSN 2016/Atual: 2525-7870 | e-ISSN 2015/2016: 2447-018X

Ainda bem que os povos indígenas, a revelia dessa violência, felizmente resistem e (re)afirmam que continuarão a existir, que querem viver e que cada indígena que nasce traz uma nova esperança.

\section{Referências}

BRUM, Eliane. In: http://www.pragmatismopolitico.com.br/2016/01/o-silencio-da-midia-emtorno-do-assassinato-brutal-de-um-bebe-indigena.html Acesso em 19.04.216.

FREIRE, Paulo. Pedagogia da Indignação: cartas pedagógicas e outros escritos. São Paulo:UNESP, 2000.

NOLASCO, Genilson. Terras, Recursos Naturais e Direitos Indígenas. In: MACHADO, Márcia (Org.). Cultura e Histórias dos Povos Indígenas: formação, direitos e conhecimento antropológico. Fortaleza: Expressão Gráfica e Editora, 2016.

ONU, Fórum Permanente das Nações Unidas para as Questões indígenas 2015. In: http://www.un.org/esa/socdev/unpfii/documentes/2015/concept-notes/youth-self-harmsuicide-es.pdf Acesso em 09.10.2016.

RAMOS Léia da Silva; MONZILAR, Eliane Boroponepa. Ser indígena no Brasil contemporâneo. Palestra ministrada na Universidade Federal do Tocantins, Campus de Arraias, TO, 2016.

SANTOS, Maria Stella de Azevedo. In: http://mundoafro.atarde.uol.com.br/tag/mae-stella-deoxossi/\#sthash.dm1goAJC.dpuf Acesso em 25.08.2016.

SANTOS, Milton. O retorno do território. OSAL, ano VI, n ${ }^{\circ}$ 16, ENERO-ABRIL, 2005

O dinheiro e o território. Território, Territórios. Programa de PósGraduação em Geografia da Universidade Federal Fluminense/Associação dos Geógrafos Brasileiros. Niterói, 2002.

SANTOS, Suelene Maria, MACHADO, Márcia, BICALHO, Poliene Soares dos Santos. Violência institucional, conflito familiar e feitiço: Suicídio entre os Iny Karajá da Aldeia de Santa Isabel. In: In: MACHADO, Márcia (Org.). Cultura e Histórias dos Povos Indígenas: formação, direitos e conhecimento antropológico. Fortaleza: Expressão Gráfica e Editora, 2016.

SAQUET, Marcos Aurélio, SPOSITO, Eliseu Savério (Orgs.). Territórios e Territorialidades: Teorias, processos e Conflitos. São Paulo: Expressão Popular, 2009. 